Original Research Article

\title{
Drug usage pattern of anti-hypertensive drugs in elderly diabetic, hypertensive in-patients with or without impaired renal function in a tertiary care hospital
}

\author{
Apeksha Bhandary*, Prasan R. Bhandari
}

Department of Pharmacology, SDM College of Medical Sciences and Hospital, Dharwad, Karnataka, India

Received: 20 January 2018 Accepted: 05 March 2018

*Correspondence to:

Dr. Apeksha Bhandary, Email: bhandary_apeksha @yahoo.com

Copyright: () the author(s), publisher and licensee Medip Academy. This is an openaccess article distributed under the terms of the Creative Commons Attribution NonCommercial License, which permits unrestricted noncommercial use, distribution, and reproduction in any medium, provided the original work is properly cited.

\begin{abstract}
Background: Hypertension (HTN) and Diabetes mellitus (DM) are the leading contributors to the cardiovascular mortality and morbidity. Drug utilisation studies (DUS) are potential tools in the evaluation in health care systems. Objectives was to analyse the drug usage pattern of anti-hypertensives in elderly hypertensive diabetic in-patients in a tertiary hospital. To analyse drug usage pattern of anti-hypertensives in elderly hypertensive, diabetic in-patients with renal impairment in a tertiary hospital.
\end{abstract}

Methods: The study population consisted of 165 hypertensive diabetic inpatients at Shri Dharmasthala Manjunatheshwara (SDM) Hospital. Questionnaire based study was conducted and prescriptions of patient with HTN and DM at and above the age of 60 years irrespective of gender were included.

Results: Our study revealed that angiotensin receptor blockers (ARBs) were the most commonly prescribed $(42.4 \%)$ class of anti-hypertensive drugs. In patients with impaired renal function also ARBs were the most common class prescribed (22.0\%). Out of 35 anti-hypertensive fixed drug combinations (FDCs) prescribed the most frequent combination was combination with an ARBs (85.7\%). There was a significant increase in the number of anti-hypertensive drugs prescribed in patients with impaired renal function when compared to patients without impaired renal function ( $\mathrm{p}<0.05)$. The cost index was high, and the percentage cost variation was more than $100 \%$ in most of the anti-hypertensive drugs prescribed.

Conclusions: This study shows that the most commonly prescribed antihypertensive drug class was ARBs in patients with and in patients without impaired renal function.

Keywords: Drug utilisation study, diabetes mellitus, elderly, hypertension, renal function

\section{INTRODUCTION}

India is the second most populous country in the world and has made a tremendous progress in the field of economy, but still today it finds itself lagging behind when compared to the health care needs of the young and the elderly. ${ }^{1}$

Elderly population in India is increasing rapidly and is expected to increase to $12.4 \%$ in the year 2026 from $5.6 \%$ in the year 1961, almost double, due to increase in the life expectancy from 32 years at the time of independence to 66.8 years in the year $2011 .^{2}$ Increase in the elderly population is also increasing the concern for their health care needs because they are constantly being crippled with chronic illness and co-morbidities. Diagnosis and treatment in the elderly patients is a challenge because they have a different physiology and physiological response to the disease and the treatment. ${ }^{3}$ Even though they are responsible for almost half the total drug usage, they are exempt from clinical trials. Due to lack of studies and clinical trials on their particular age group, they are being prescribed drugs based on the guidelines for younger generation. ${ }^{4}$ 
HTN and DM are the leading contributor to the global burden of cardiovascular morbidity and mortality. ${ }^{5}$ Prevalence of DM in India is estimated to increase to 57.2 million in the year $2025 .{ }^{6}$ Every fifth person in India is a diabetic and is expected to pick up the distinction of having the highest number of diabetics in the world by the year 2025-World's capital of DM. ${ }^{6,1}$ Prevalence of HTN in India in the year 2000 was 60.4 million males and 57.8 million females and is expected to increase to 107.3 million and 106.2 million by the year $2025 .^{7}$ These two enormous diseases come hand in hand with each other. About $75 \%$ adults with DM have HTN and hypertensives often show signs of insulin resistance. HTN and DM are common, interlinked diseases that share a significant overlap in risk factors and complications. ${ }^{1}$

The renal excretory function begins to decline by the 3rd and $4^{\text {th }}$ decade and by the 6 th decade glomerular filtration rate (GFR) declines by $1-2 \mathrm{ml} / \mathrm{min} /$ year. The age related decline in renal function is proportional to blood pressure (BP) level. ${ }^{8}$ Control of $\mathrm{BP}$ and blood sugar (BS) is important to decrease the progression of diabetic nephropathy(DN) to end stage renal disease(ESRD).The Joint National Committee (JNC) recommends that the target BP should be $<130 / 80 \mathrm{mmHg}$ in patients with HTN and $\mathrm{DM}$ with chronic kidney disease(CKD). ${ }^{9}$ Higher risk of chronic illness in elderly increases the chances of taking multiple drugs by elderly people, increases the burden on the kidney for its excretion in a kidney that is already declining due to the ageing process. ${ }^{6,8}$

DUS can identify the frequent prescribing errors, their causes, the deviation from the guidelines, and the cost effectiveness. In our present study we intend to:

- Analyse the drug usage pattern of anti-hypertensives in elderly hypertensive diabetic in-patients in a tertiary hospital.

- Analyse drug usage pattern of anti-hypertensives in elderly hypertensive, diabetic in-patients with renal impairment in a tertiary hospital.

\section{METHODS}

\section{Study design}

It was a prospective, observational study carried out at medicine wards in SDM College of Medical Sciences and Hospital, Karnataka. The study protocol was approved by the Institutional ethics committee (IEC). A total of 165 hypertensive and diabetic patients clinically diagnosed as per JNC 7 and American Diabetes Association (ADA) at SDM Medicine wards were enrolled. All the patients were explained clearly about the nature and purpose of the study in their own language and consent was taken.

\section{Inclusion criteria}

- Patients of either sex at and above 60 years admitted in the medicine wards diagnosed with HTN and DM and were on treatment with anti-hypertensives were included.

- Patients whose renal profile (Serum creatinine) is available after their admission to the hospital were included.

\section{Exclusion criteria}

- Patients less than 60 years of age.

- Patients diagnosed with HTN or DM but not both.

- Patients whose renal profile data was not available.

- Patient/ relative who were not willing to give their consent or were unable to give consent.

- No sufficient data (age, registration number) were available.

- Patients having emergency/life threatening medical/ surgical conditions were excluded.

\section{Sample size}

The primary objective of the study was to analyse the drug usage pattern of anti-hypertensives in elderly hypertensive diabetic in-patients in a tertiary hospital. The prevalence rate of hypertension in diabetic patient is $70 \%$ and taking allowable error as $10 \%$ of positive character, 165 patients were needed to give an estimate at a width of $5 \%$ and with $95 \%$ confidence interval. ${ }^{10,11}$

\section{Participants and data colllection}

A questionnaire-based study was conducted at the medicine wards. Prescriptions of clinically diagnosed HTN and DM patients at and above the age of 60 years admitted in the medicine wards were included. The questionnaire consisted patient's demographics like age, gender, marital status, religion and registration number. Patient's diagnosis was made as per JNC 7 and ADA 2015. Co-morbidities, if any, listed as per cardiovascular system (CVS), respiratory system (RS), central nervous system (CNS) and locomotor system. Presence of hypertensive/ diabetic retinopathy (DR) or any other changes in the eye due to HTN and DM were noted. Prescription details like date, number of drugs, name of individual drugs (generic/branded), FDC prescribed, dose, dosage form, dosing schedule and duration of treatment were noted down in the questionnaire. The cost of the drugs prescribed from hospital schedule was calculated based on rate available in hospital drug store and lowest available was based on national drug index. ${ }^{12,13}$ Cost ratio between the maximum and minimum cost of the same drug manufactured by different pharmaceutical companies was calculated as follows: Cost ratio= Maximum cost among prescribed drugs/Minimum cost available in the market. Percentage cost variation was calculated as follows: $\%$ cost variation $=($ Max cost - Min cost $) \times 100$ Min cost.${ }^{14}$ Renal function tests were obtained and creatinine clearance $(\mathrm{Cr}$. $\mathrm{Cl}$ ) calculated using Cockroft-Gault equation. ${ }^{15} \mathrm{BP}$ recording and BS levels, (Random blood sugar (RBS), fasting blood sugar (FBS), and glycosylated haemoglobin $(\mathrm{HbA} 1 \mathrm{c})$, if done, then the values were noted. 


\section{Data analysis}

Descriptive statistics was applied. Data was analysed by proportion and percentages and comparison done using chi-square test using Statistical Package for the Social Sciences (SPPS) software version 24.

\section{RESULTS}

A total of 165 patients were analyzed for various parameters during the tenure of this study in the Medicine wards of SDM College of Medical Sciences and Hospital, Dharwad.

\section{Demographic data}

In this study it was found that, the percentage of male and female patients was $56.97 \%(n=94)$ and $43.03 \%(n=71)$ (Figure 1).

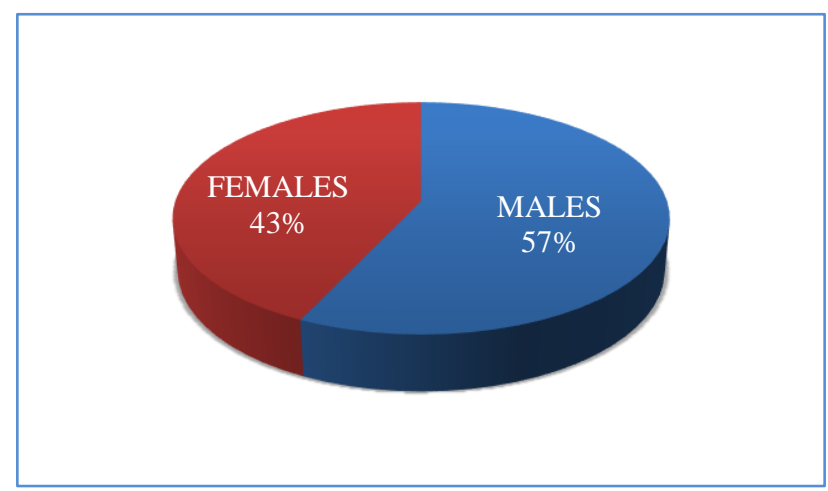

Figure 1: Gender-wise distribution (\%) of study participants.

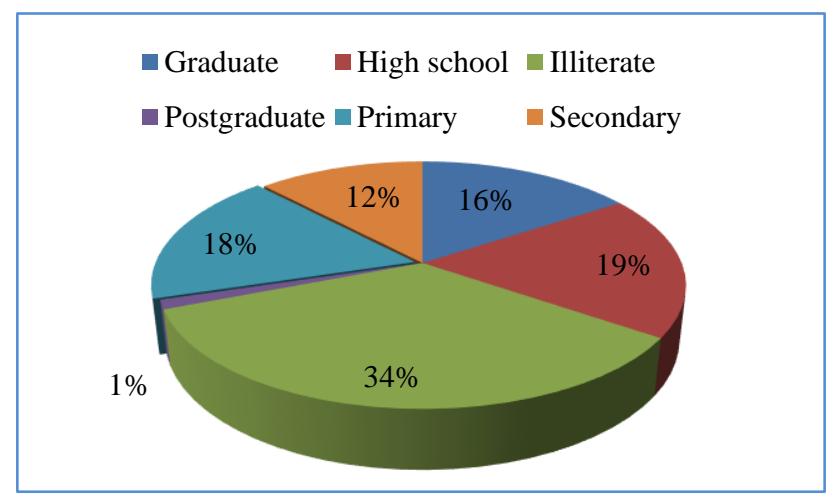

Figure 2: Education-wise distribution (\%) of study participants.

Out of the study population $57(34.55 \%)$ were illiterates, whereas primary education was $17.58 \% \quad(n=29)$, high school $18.79 \% \quad(n=31)$, secondary education $12.12 \%$ $(n=20)$, graduates $15.76 \%(n=26)$, postgraduates $1.21 \%$ $(n=2)$ (Figure 2).

According to Modified B.G. Prasad Classification, majority $64(38.79 \%)$ study participants were of class IV socio-economic status, followed by $45(27.27 \%)$ class II socioeconomic status and very few $4(2.42 \%)$ were of class $\mathrm{V}$ socioeconomic class (Figure 3).In this study majority 77 $(46.67 \%)$ of patients were from the age group 60-65 years, followed by $45(27.27 \%)$ in the age group of 66-70 age years. Only $8(4.85 \%)$ were more than 80 years old. Average age was $67.34 \pm 6.91$ years (Figure 4 ).

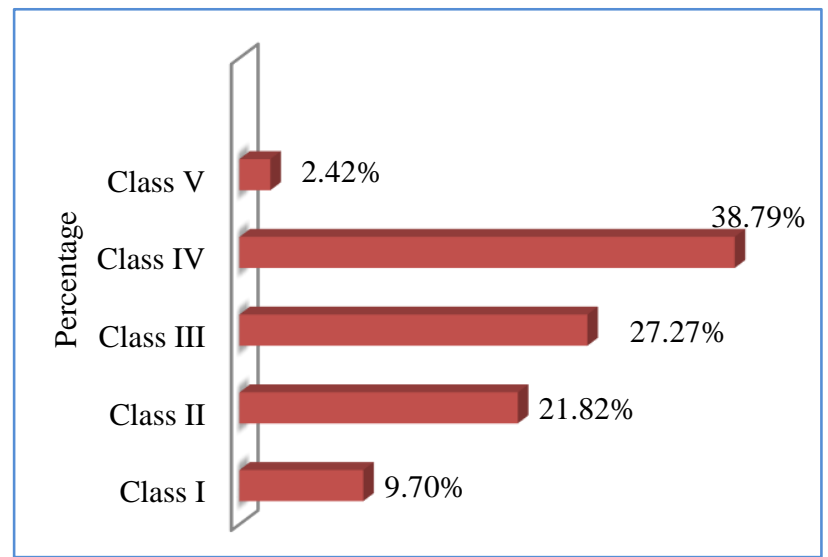

Figure 3: Distribution of participants (\%) as per socio-economic status.

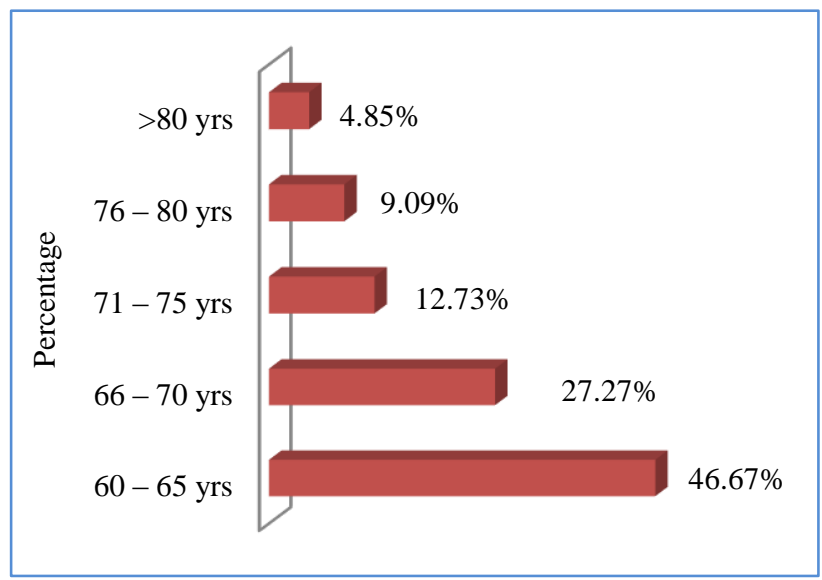

Figure 4: Age-wise distribution (\%) of study participants.

\section{Co morbidities}

In the study population majority 60 (36.4\%), co morbidities where of CNS system, followed by CVS, 46 $(27.9 \%)$, followed by RS, $44(26.7 \%)$, and lastly of the locomotor system, 30 (16.4\%). Among CNS, old Cerebrovascular accident (CVA) was in majority 34 $(20.6 \%)$ (Figure 5). In the study population, $51.5 \%(n=85)$ participants underwent fundoscopy. Among 85 patients DR was seen in $72.94 \%(n=62)$ patients and hypertensive retinopathy was seen in $63.52 \%(n=54)$. The majority, 40 $(47.1 \%)$ among DR was bilateral (B/L) mild nonproliferative diabetic retinopathy (NPDR), followed by $\mathrm{B} / \mathrm{L}$ moderate NPDR. Among hypertensive retinopathy $\mathrm{B} / \mathrm{L}$ grade 1 was seen in majority $40(47.1 \%)$ of the study population. No other changes in the eye were noticed due 
to HTN and DM in this study population (Figure 6 and 7). In the study population majority $88(53.33 \%)$ of the patients had impaired renal function and 77 (46.67\%) of patients had normal renal function (Figure 8).

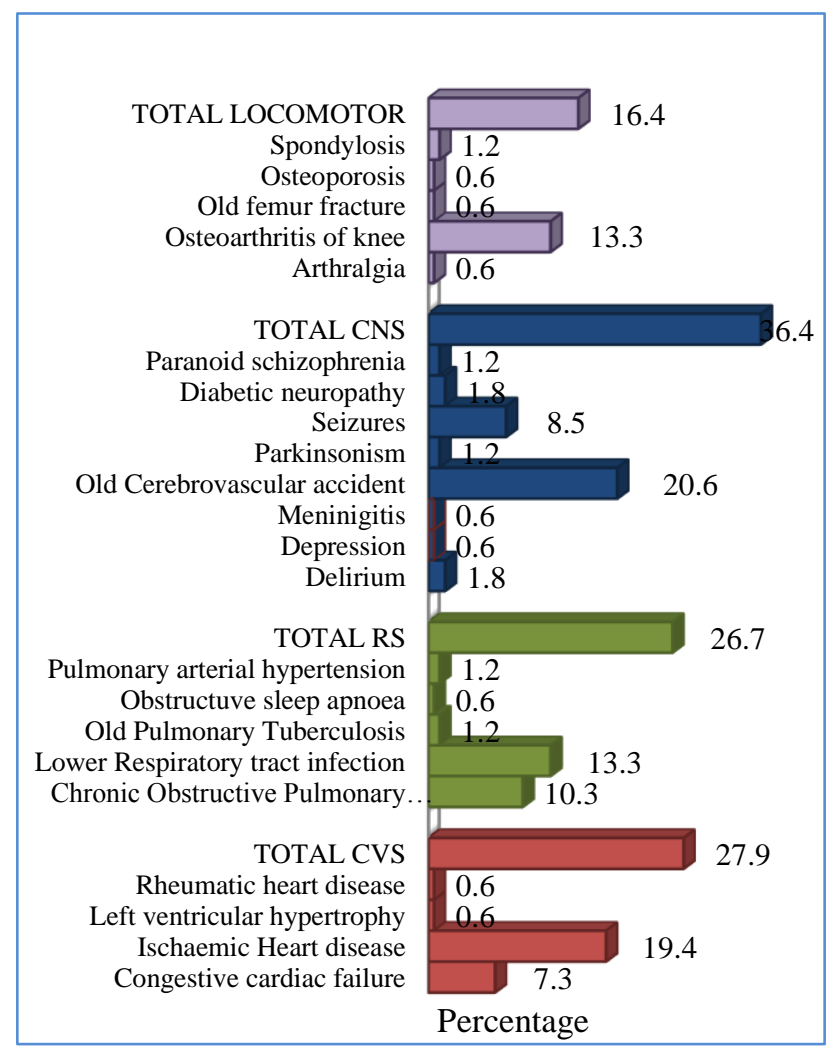

Figure 5: Co morbidities (\%) in the study population.

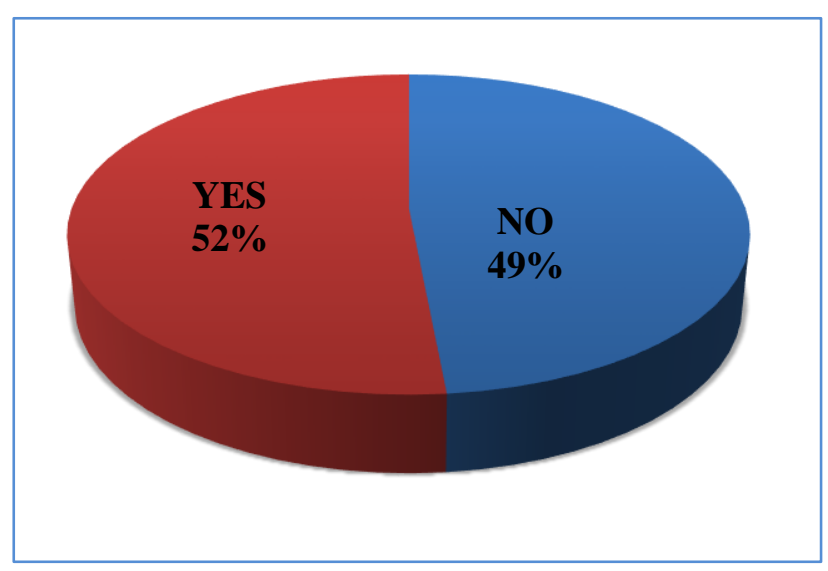

Figure 6: Fundoscopic findings (\%) of the study population.

\section{Anti-hypertensive drugs}

Among the 165-study population 106 patients medications were not changed after admission and continued the same line of anti-hypertensive drugs, whereas 27 patients medications were changed, among which 10 patients another class of anti-hypertensive drugs were added (Table $1)$.
A total of 191 anti-hypertensive drugs excluding the FDCs were prescribed for 165 patients. Among which anatomical therapeutic classification (ATC) class C09C (ARB II, plain) was used in majority $42.4 \%(n=81)$, of which telmisartan was used more frequently $(34.5 \%)$, followed by $\mathrm{C} 08 \mathrm{C}$ (Selective calcium channel blocker (CCB) with vascular effects) $34.55 \%(n=66)$, out of which amlodipine was frequently used $(25.65 \%)$. Among patients with impaired renal function too class C09C was frequently used $(18.8 \%)$ with telmisartan being the commonest drug prescribed (18.8\%) (Table 2).

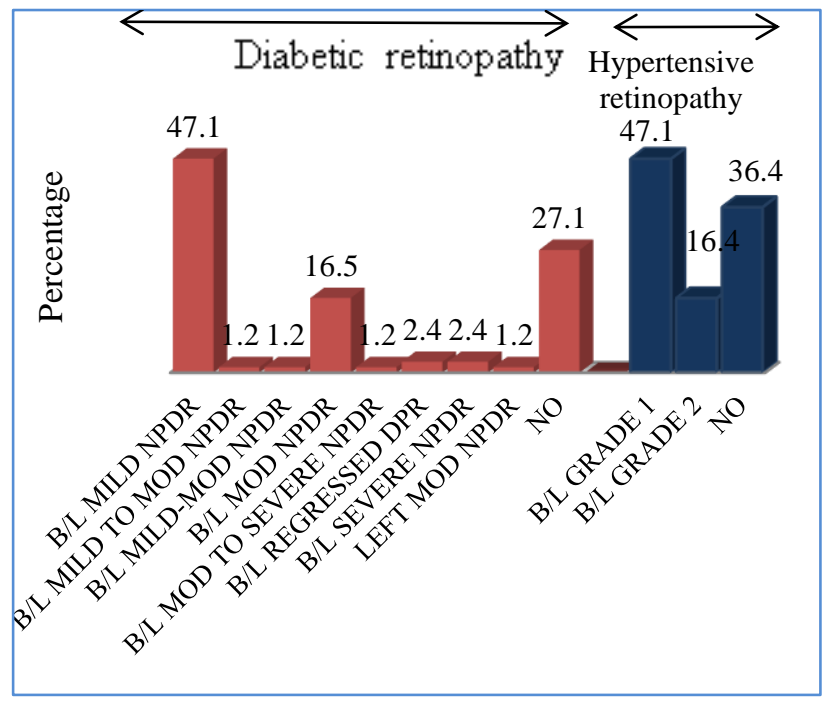

Figure 7: Hypertensive and diabetic retinopathy (\%) in the study participants.

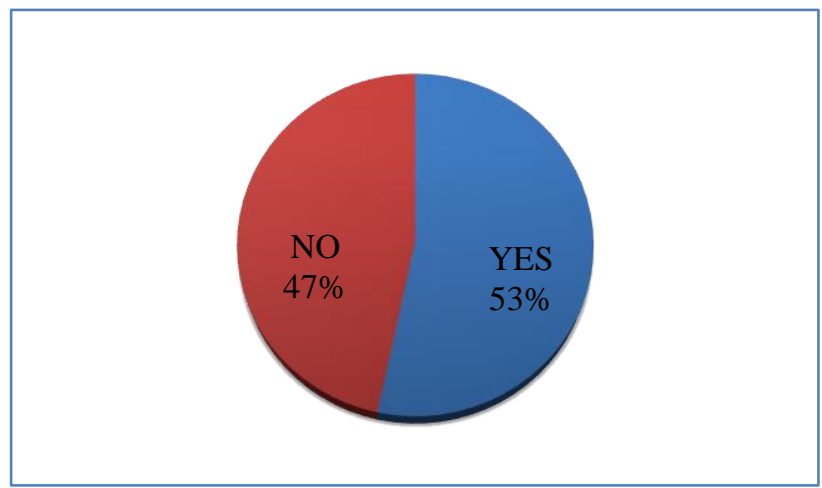

Figure 8: Impaired renal function (\%) in the study participants.

\section{Dose and route of administration}

The mean prescribed daily dose (PDD) / defined daily dose (DDD) for the most commonly prescribed drugs telmisartan and amlodipine was $1.12 \pm 0.52$ in our study population. In patients with impaired renal function the mean PDD/DDD for telmisartan and amlodipine was 1.22 \pm 0.68 . Mean PDD/DDD ranged between (0.03-3.33), least being for labetalol and maximum for nifedipine. The range of PDD/DDD for drugs with impaired renal function was (0.03-3.33) (Table 3). 
Table 1: Study participants whose anti-hypertensive medications were changed after admission.

\begin{tabular}{|llll|l|}
\hline Changed & Changed and added & Not changed & Not changed and added & Reduced \\
\hline 17 & 10 & 106 & 29 & 3 \\
\hline
\end{tabular}

Table 2: Anti-hypertensives prescribed to the study population.

\begin{tabular}{|c|c|c|c|c|c|c|c|c|c|c|c|c|c|}
\hline \multicolumn{7}{|c|}{$\begin{array}{l}\text { Class/ anatomical therapeutic classification } \\
\text { (ATC) }\end{array}$} & \multicolumn{7}{|l|}{ Generic name } \\
\hline \multirow{3}{*}{ ATC } & \multirow{2}{*}{\multicolumn{2}{|c|}{ Total }} & \multicolumn{4}{|c|}{ Impaired renal function } & & \multirow{2}{*}{\multicolumn{2}{|c|}{ Total }} & \multicolumn{4}{|c|}{ Impaired renal function } \\
\hline & & & \multicolumn{2}{|c|}{ Yes } & \multicolumn{2}{|c|}{ No } & & & & \multicolumn{2}{|c|}{ Yes } & \multicolumn{2}{|c|}{ No } \\
\hline & $\mathbf{n}$ & $\%$ & $\mathbf{n}$ & $\%$ & $\mathrm{n}$ & $\%$ & & $\mathbf{n}$ & $\%$ & $\mathbf{F}$ & $\%$ & $\mathbf{F}$ & $\%$ \\
\hline C01D & 2 & 1.05 & 2 & 1.0 & 0 & 0.0 & C01DA02 - Nitroglycerin & 2 & 1.05 & 2 & 1.0 & 0 & 0.0 \\
\hline \multirow{2}{*}{$\mathrm{C} 02 \mathrm{~A}$} & \multirow{2}{*}{4} & \multirow{2}{*}{2.09} & \multirow{2}{*}{4} & \multirow{2}{*}{2.1} & \multirow{2}{*}{0} & \multirow{2}{*}{0.0} & C02AC01 - Clonidine & 2 & 1.05 & 2 & 1.0 & 0 & 0.0 \\
\hline & & & & & & & C02AC05 - Moxonidine & 2 & 1.05 & 2 & 1.0 & 0 & 0.0 \\
\hline $\mathrm{C} 02 \mathrm{C}$ & 2 & 1.05 & 2 & 1.0 & 0 & 0.0 & C02CA01 - Prazosin & 2 & 1.05 & 2 & 1.0 & 0 & 0.0 \\
\hline \multirow{2}{*}{ C03B } & \multirow{2}{*}{4} & \multirow{2}{*}{2.09} & \multirow{2}{*}{3} & \multirow{2}{*}{1.6} & \multirow{2}{*}{1} & \multirow{2}{*}{0.5} & C03BA04 - Chlorthalidone & 1 & 0.52 & 0 & 0.0 & 1 & 0.5 \\
\hline & & & & & & & C03BA08 - Metolazone & 3 & 1.57 & 3 & 1.6 & 0 & 0.0 \\
\hline \multirow{4}{*}{ C07A } & \multirow{4}{*}{25} & \multirow{4}{*}{13.0} & \multirow{4}{*}{16} & \multirow{4}{*}{8.4} & & & C07AB02 - Metoprolol & 14 & 7.33 & 7 & 3.7 & 7 & 3.7 \\
\hline & & & & & & & C07AB03 - Atenolol & 1 & 0.52 & 1 & 0.5 & 0 & 0.0 \\
\hline & & & & & 9 & 4.7 & C07AG01 - Labetalol & 3 & 1.57 & 3 & 1.6 & 0 & 0.0 \\
\hline & & & & & & & C07AG02 - Carvedilol & 7 & 3.66 & 5 & 2.6 & 2 & 1.0 \\
\hline & & & & & & & C08CA01 - Amlodipine & 49 & 25.65 & 25 & 13.1 & 24 & 12.6 \\
\hline $\mathrm{COBC}$ & 66 & 3455 & 34 & 178 & 32 & 168 & C08CA01 - S-Amlodipine & 1 & 0.52 & 0 & 0.0 & 1 & 0.5 \\
\hline - & 00 & J & 34 & 111.0 & J2 & 10.0 & C08CA05 - Nifedipine & 1 & 0.52 & 1 & 0.5 & 0 & 0.0 \\
\hline & & & & & & & C08CA14 - Cilnidipine & 14 & 7.33 & 7 & 3.7 & 7 & 3.7 \\
\hline CoO & & & & & & & C09AA02 - Enalapril & 2 & 1.05 & 2 & 1.0 & 0 & 0.0 \\
\hline CU9A & 1 & 3.00 & 5 & 2.0 & 2 & 1.0 & C09AA05 - Ramipril & 5 & 2.62 & 3 & 1.6 & 2 & 1.0 \\
\hline & & & & & & & C09CA01 - Losartan & 10 & 5.24 & 4 & 2.1 & 6 & 3.1 \\
\hline $\mathrm{C} 09 \mathrm{C}$ & 81 & 42.4 & 42 & 22.0 & 39 & 20.4 & C09CA07 - Telmisartan & 66 & 34.5 & 36 & 18.8 & 30 & 15.7 \\
\hline & & & & & & & C09CA08 - Olmesartan & 6 & 3.14 & 3 & 1.6 & 3 & 1.6 \\
\hline Total & 191 & 100.0 & 108 & 56.5 & 83 & 43.5 & Total & 191 & 100 & 108 & 56.5 & 83 & 43.5 \\
\hline
\end{tabular}

Among the 191 anti-hypertensive drugs prescribed majority of drugs were on once daily dosing (OD) 171 (89.53\%), followed by twice daily (BD) 7.335 (14). The most common route of administration was oral route $97.38 \%$ (186). Only five $(2.62 \%)$ drugs were given by intravenous (IV) route (Table 4).

\section{FDC}

A total of 35 anti-hypertensive FDCs were prescribed for 165 patients. Among which ATC class C09D (ARB II, combination) was used in majority $85.7 \%$ (30) of which telmisartan + hydrochlorothiazide (HCT) was used more frequently (34.29\%). This class was followed by C07F ( $\beta$ blocker + other combination) $11.4 \%$ (4), out of which Amlodipine + Atenolol was frequently used (11.4\%).

Among patients with impaired renal function too, class C09D was frequently used (51.4\%), with telmisartan + HCT being the commonest drug prescribed (25.7\%) (Table 5). Among the 35 anti-hypertensive FDCs prescribed, majority of drugs were on OD dosing 34 (97.1\%). All the FDCs were given by oral route of administration (Table 6).

\section{Monotherapy and polytherapy}

In our study, $61.2 \% \quad(\mathrm{~N}=101)$ patients were on monotherapy. Among patients with impaired renal function $30.91 \% \quad(\mathrm{~N}=51)$ were on monotherapy. The maximum number of drugs/patient including active drugs in FDCs were six in patients with impaired renal function and four in patients with normal renal function (Table 7).

A 33 patients received FDCs among which 18 patients had impaired renal function (Table 8).

There was significant increase in the number of drugs including the active drugs in FDCs in patients with impaired renal function when compared to patients without impaired renal function. $(\mathrm{p}=<0.05)$ (Table 9).

\section{Cost analysis}

Among the prescribed drugs the maximum variation was seen with the drug metoprolol $50 \mathrm{mg}$, the cost ratio was 27.83 and the percentage cost variation that was $2642.6 \%$. 
Table 3: Average prescribed drug dose (PDD)/defined drug dose (DDD) of anti-hypertensive drugs in the study population.

\begin{tabular}{|llll|}
\hline \multicolumn{2}{|l}{ Avg. PDD/DDD } & \multicolumn{2}{l|}{$\begin{array}{l}\text { Impaired renal } \\
\text { function }\end{array}$} \\
\cline { 2 - 4 } & Total & Yes & No \\
\hline Amlodipine & $1.12 \pm 0.52$ & $1.22 \pm 0.68$ & $1.02 \pm 0.23$ \\
\hline Atenolol & $0.67 \pm 0.00$ & $0.67 \pm 0.00$ & - \\
\hline Carvedilol & $0.15 \pm 0.03$ & $0.15 \pm 0.04$ & $0.17 \pm 0.00$ \\
\hline Chlorthalidone & $0.50 \pm 0.00$ & - & $0.50 \pm 0.00$ \\
\hline Cilnidipine & $1.00 \pm 0.00$ & $1.00 \pm 0.00$ & $1.00 \pm 0.00$ \\
\hline Clonidine & $0.44 \pm 0.00$ & $0.44 \pm 0.00$ & - \\
\hline Enalapril & $0.50 \pm 0.00$ & $0.50 \pm 0.00$ & - \\
\hline Labetalol & $0.03 \pm 0.03$ & $0.03 \pm 0.03$ & - \\
\hline Losartan & $0.90 \pm 0.21$ & $1.00 \pm 0.00$ & $0.83 \pm 0.26$ \\
\hline Metolazone & $0.83 \pm 0.29$ & $0.83 \pm 0.29$ & - \\
\hline Metoprolol & $0.29 \pm 0.14$ & $0.21 \pm 0.08$ & $0.36 \pm 0.15$ \\
\hline Moxonidine & $2.17 \pm 1.18$ & $2.17 \pm 1.18$ & - \\
\hline Nifedipine & $3.33 \pm 0.00$ & $3.33 \pm 0.00$ & - \\
\hline Nitroglycerin & $1.33 \pm 0.52$ & $1.33 \pm 0.58$ & $1.33 \pm 0.58$ \\
\hline Olmesartan & $1.25 \pm 1.06$ & $1.25 \pm 1.06$ & - \\
\hline Prazosin & $1.20 \pm 0.45$ & $1.00 \pm 0.00$ & $1.50 \pm 0.71$ \\
\hline Ramipril & $1.0 \pm 0.00$ & - & $1.0 \pm 0.00$ \\
\hline S-Amlodipine & $0.99 \pm 0.06$ & $1.00 \pm 0.00$ & $0.98 \pm 0.09$ \\
\hline Telmisartan & $1.12 \pm 0.52$ & $1.22 \pm 0.68$ & $1.02 \pm 0.23$ \\
\hline & & & \\
\hline & & & \\
\hline
\end{tabular}

The minimum variation was seen with drugs atenolol, losartan and nitroglycerin, where the cost index was 1.00 and cost variation $0 \%$ (Table 10). Among the FDCs prescribed the maximum variation was seen with the combination of telmisartan + amlodipine, where the cost ratio was 10.36 and percentage cost variation was $935.8 \%$. The minimum variation was seen with the combination of chlorthalidone + telmisartan + cilnidipine, where the cost index was 1.11 and percentage cost variation was $11.0 \%$ (Table 11).

Among the different classes it was found that class C08C -CCBs was the most cost effective with Rs. 3.96 \pm 2.43 /day in relation to other class of anti-hypertensives prescribed. The ranking in terms of cost/day from the lowest to highest found in this study were C08C-CCBs <C09A-ACEIs $<$ C09C-ARB <C02A-Centrally acting anti-adrenergic drugs $<$ C03B-Low ceiling diuretics excluding thiazides $<$ C02C-anti-adrenergic agents-peripherally acting < C01D -vasodilators <C07A- $\beta$ blockers (Table 12).

Table 4: Frequency and route of administration of anti-hypertensive drugs prescribed to the study population.

\begin{tabular}{|c|c|c|c|c|c|}
\hline Frequency & n & $\%$ & Route & $\mathbf{n}$ & $\%$ \\
\hline 1/2/DAY & 1 & 0.52 & \multirow{2}{*}{ IV } & \multirow{2}{*}{5} & \multirow{2}{*}{2.62} \\
\hline OD & 171 & 89.53 & & & \\
\hline $\mathrm{BD}$ & 14 & 7.33 & \multirow{2}{*}{ Oral } & \multirow{2}{*}{186} & \multirow{2}{*}{97.38} \\
\hline TID & 1 & 0.52 & & & \\
\hline 5/DAY & 1 & 0.52 & \multirow{2}{*}{ Total } & \multirow{2}{*}{191} & \multirow{2}{*}{100.00} \\
\hline Total & 191 & 100.00 & & & \\
\hline
\end{tabular}

Table 5: Anti-hypertensive FDCs prescribed to the study population.

\begin{tabular}{|c|c|c|c|c|c|c|c|c|c|c|c|c|c|}
\hline \multicolumn{7}{|c|}{ Class/ATC classification } & \multicolumn{7}{|l|}{ Generic name } \\
\hline \multirow{3}{*}{ ATC } & \multirow{2}{*}{\multicolumn{2}{|c|}{ Total }} & \multicolumn{4}{|c|}{ Impaired Renal Function } & \multirow[b]{3}{*}{ Drug name } & \multirow{2}{*}{\multicolumn{2}{|c|}{ Total }} & \multicolumn{4}{|c|}{$\begin{array}{l}\text { Impaired Renal } \\
\text { Function }\end{array}$} \\
\hline & & & \multicolumn{2}{|c|}{ Yes } & \multicolumn{2}{|l|}{ No } & & & & \multicolumn{2}{|c|}{ Yes } & \multicolumn{2}{|l|}{ No } \\
\hline & $\mathbf{n}$ & $\%$ & $\mathbf{n}$ & $\%$ & $\mathbf{n}$ & $\%$ & & $\mathbf{n}$ & $\%$ & $\mathbf{n}$ & $\%$ & n & $\%$ \\
\hline \multirow[b]{2}{*}{$\mathrm{C} 07 \mathrm{~F}$} & \multirow[b]{2}{*}{4} & \multirow[b]{2}{*}{11.4} & \multirow[b]{2}{*}{1} & \multirow[b]{2}{*}{2.9} & \multirow[b]{2}{*}{3} & \multirow[b]{2}{*}{8.6} & C07FB-Atenolol + Amlodipine & 3 & 8.57 & 1 & 2.9 & 2 & 5.7 \\
\hline & & & & & & & $\begin{array}{l}\text { C07FB13-Metoprolol + } \\
\text { Amlodipine }\end{array}$ & 1 & 2.86 & 0 & 0.0 & 1 & 2.9 \\
\hline $\mathrm{C} 08 \mathrm{G}$ & 1 & 2.9 & 1 & 2.9 & 0 & 0.0 & C08GA02-Amlodipine+ HCT & 1 & 2.86 & 1 & 2.9 & 0 & 0.0 \\
\hline \multirow{9}{*}{ C09D } & \multirow{9}{*}{30} & \multirow{9}{*}{85.7} & \multirow{9}{*}{18} & \multirow{9}{*}{51.4} & \multirow{9}{*}{12} & \multirow{9}{*}{34.3} & $\begin{array}{l}\text { C09D-Chlorthalidone }+ \\
\text { Telmisartan }+ \text { Cilnidipine }\end{array}$ & 1 & 2.86 & 0 & 0.0 & 1 & 2.9 \\
\hline & & & & & & & $\begin{array}{l}\text { C09D-HCT }+ \text { Telmisartan }+ \\
\text { Amlodipine }\end{array}$ & 2 & 5.71 & 2 & 5.7 & 0 & 0.0 \\
\hline & & & & & & & C09D-Losartan + HCT & 4 & 11.4 & 2 & 5.7 & 2 & 5.7 \\
\hline & & & & & & & C09D-Metoprolol+ Telmisartan & 2 & 5.71 & 1 & 2.9 & 1 & 2.9 \\
\hline & & & & & & & C09D-Olmesartan+ Amlodipine & 1 & 2.86 & 0 & 0.0 & 1 & 2.9 \\
\hline & & & & & & & C09D-Olmesartan+ HCT & 1 & 2.86 & 1 & 2.9 & 0 & 0.0 \\
\hline & & & & & & & $\begin{array}{l}\text { C09D-Telmisartan }+ \\
\text { Chlorthalidone }\end{array}$ & 1 & 2.86 & 1 & 2.9 & 0 & 0.0 \\
\hline & & & & & & & C09DA07-Telmisartan + HCT & 12 & $\begin{array}{l}34.2 \\
9\end{array}$ & 9 & 25.7 & 3 & 8.6 \\
\hline & & & & & & & $\begin{array}{l}\text { C09DB04-Telmisartan }+ \\
\text { Amlodipine }\end{array}$ & 6 & $\begin{array}{l}17.1 \\
4\end{array}$ & 2 & 5.7 & 4 & 11.4 \\
\hline Total & 35 & 100 & 20 & 57.1 & 15 & 42.9 & Total & 35 & 100 & 20 & 57.1 & 15 & 42.9 \\
\hline
\end{tabular}


Table 6: Frequency and route of administration of anti-hypertensive FDCS prescribed to the study population.

\begin{tabular}{|c|c|c|c|c|c|}
\hline Frequency & n & $\%$ & Route & $\mathbf{n}$ & $\%$ \\
\hline 1/2/DAY & 1 & 2.9 & \multirow{2}{*}{ Oral } & \multirow{2}{*}{35} & \multirow{2}{*}{100.00} \\
\hline OD & 34 & 97.1 & & & \\
\hline Total & 35 & 100.0 & Total & 35 & 100.00 \\
\hline
\end{tabular}

Table 7: Number of drugs including active drugs in FDCs/ patient.

\begin{tabular}{|lllllll|}
\hline & & \multicolumn{5}{c|}{ Impaired renal function } \\
\hline & $\mathbf{N}$ & $\mathbf{\%}$ & $\mathbf{N}$ & $\mathbf{\%}$ & $\mathbf{N}$ & $\mathbf{\%}$ \\
\hline Monotherapy & 101 & 61.2 & 51 & 30.91 & 50 & 30.30 \\
\hline Polytherapy & & & & & & \\
\hline 2 & 41 & 24.8 & 23 & 13.94 & 18 & 10.91 \\
\hline 3 & 15 & 9.1 & 7 & 4.24 & 8 & 4.85 \\
\hline 4 & 5 & 3.0 & 4 & 2.42 & 1 & 0.61 \\
\hline 5 & 2 & 1.2 & 2 & 1.21 & 0 & 0.00 \\
\hline 6 & 1 & 0.6 & 1 & 0.61 & 0 & 0.00 \\
\hline Total & 165 & 100 & 88 & 53.33 & 77 & 46.67 \\
\hline
\end{tabular}

Table 8: Number of FDC/patient.

\begin{tabular}{|lllllll|}
\hline & & & \multicolumn{3}{l}{ Impaired renal function } \\
\hline & & & Yes & \multicolumn{3}{c|}{ No } \\
\hline & N & \% & N & \% & N & \% \\
\hline 0 & 132 & 80.0 & 70 & 42.42 & 62 & 37.58 \\
\hline 1 & 31 & 18.8 & 16 & 9.70 & 15 & 9.09 \\
\hline 2 & 2 & 1.2 & 2 & 1.21 & 0 & 0.00 \\
\hline Total & 165 & 100.0 & 88 & 53.33 & 77 & 46.67 \\
\hline
\end{tabular}

Table 9: Anti-hypertensive drugs including active drugs in FDCs used in patients with impaired renal function v/s patients with normal renal function.

\begin{tabular}{|lllll|}
\hline \multirow{2}{*}{$\begin{array}{l}\text { Anti- } \\
\text { hypertensive } \\
\text { drugs }\end{array}$} & $\begin{array}{l}\text { Renal } \\
\text { function }\end{array}$ & $\begin{array}{l}\text { No. of } \\
\text { drugs } \\
\text { used }\end{array}$ & $\begin{array}{l}\text { No. of } \\
\text { drugs not } \\
\text { used }\end{array}$ & p value \\
\cline { 2 - 4 } & Impaired & 150 & 114 & $\begin{array}{l}\mathrm{x}^{2}=9.82, \\
* \mathrm{p}= \\
0.00173\end{array}$ \\
\cline { 2 - 5 } & Normal & 114 & 150 & \\
\hline
\end{tabular}

$* \mathrm{p}<0.05$ was considered significant.

Among the different FDCs prescribed C07F - $\beta$ blocker + CCB was most cost effective when compared to other classes of anti-hypertensive FDCs prescribed. The ranking in terms of cost/day of FDC from the lowest to highest found in this study were C07F $-\beta$ blocker + CCB $<$ C08G $\mathrm{CCB}+$ Diuretics <combination with an ARB (Table 13).

\section{BP, blood sugar levels and HbAlc}

Out of 165 patients, 98 patients BP were under control (BP-100-139/71-89mmHg) and 67 were not under control
(BP $<100 / 70 \mathrm{mmHg}$ or $>140 / 90 \mathrm{mmHg}$ ). Number of patients with impaired renal function whose BP was not under control were 43 . There was significant difference in patients with BP not under control among patients with impaired renal function patient and patients with normal renal function $(\mathrm{p}<0.05)$. The RBS levels were under control $(\mathrm{RBS}=101-200 \mathrm{mg} / \mathrm{dl})$ in 80 patients and were not under control $(\mathrm{RBS}=<100 \mathrm{mg} / \mathrm{dl}$ or $>201 \mathrm{mg} / \mathrm{dl})$ in 85 patients. RBS was not under control in 51 patients among those with impaired renal function. There was no significant difference in patients with RBS not under control among patients with impaired renal function and patients with normal renal function $(\mathrm{p}>0.05)$. HbA1C was done in 57 patients. There was no significant difference in HbA1C $>6.5 \%$ among patients with impaired renal function and patients with normal renal function $(p>0.05)$ (Table 14).

The average number of days stayed in the hospital per patient was $8.64 \pm 6.98$. In patients with impaired renal function the mean number of days stayed in the hospital is $8.73 \pm 7.4$ (Table 15).

\section{World health organisation (WHO) indicators}

As per world health organisation (WHO) indicators average number of drugs per patient $1.60 \pm 0.936$ and in patients with impaired renal function was $1.70 \pm 1.074$. The percentage of encounters with injection was $2.21 \%$. The percentage of drugs prescribed by generic names was $8.85 \%$, and percentage of drugs prescribed from the essential drug list 2015 was $32.30 \%$ (Table 16).

\section{DISCUSSION}

\section{Demographics}

In the present study we found that majority of patients were males $(56.97 \%)$ compared to that of females (43.03\%) which was similar to the study conducted by Abraham et al, where majority $(65.36 \%)$ were males compared to females (34.64\%). ${ }^{16}$ The average age in our study was $67.34 \pm 6.91$ years, whereas study by Nayaka et.al., the average age was 72.68 years. ${ }^{17} \mathrm{~A} 34.55 \%$ of patients were illiterate $38.79 \%$ belonged to category of lower middle and $9.7 \%$ to upper socioeconomic classes compared to study by Nayaka et al, where $93 \%$ of patients were illiterate, $68 \%$ belonged to category of lower and $12 \%$ to higher socioeconomic classes. ${ }^{17}$

\section{Co morbidities}

Majority $36.4 \%$, of the co morbidities were of CNS system, followed by CVS, $27.9 \%$, RS $26.7 \%$, whereas in study conducted by Nayaka et al, majority of co morbidities were seen in $\mathrm{RS} 66.67 \%$, followed by endocrine, $35.33 \%$, CVS, $32.67 \% .^{17}$ 
Table 10: Cost variation among prescribed drugs and cheapest available.

\begin{tabular}{|c|c|c|c|c|c|}
\hline Drug name & Dose & $\begin{array}{l}\text { Max/10 tab or per } \\
\text { Inj. }\end{array}$ & $\begin{array}{l}\text { Min/10 tab or per } \\
\text { Inj. }\end{array}$ & Cost ratio & $\begin{array}{l}\% \text { Cost } \\
\text { variation }\end{array}$ \\
\hline \multirow{3}{*}{ Tab. Amlodipine } & $2.5 \mathrm{mg}$ & Rs.31.97 & Rs.5.2 & 6.15 & 514.8 \\
\hline & $5 \mathrm{mg}$ & Rs.24.46 & Rs.2.68 & 9.13 & 812.7 \\
\hline & $10 \mathrm{mg}$ & Rs.70 & Rs.7.8 & 8.97 & 797.4 \\
\hline Tab. Atenolol & $50 \mathrm{mg}$ & Rs.3.34 & Rs.3.34 & 1.00 & 0.0 \\
\hline \multirow{2}{*}{ Tab. Carvedilol } & $3.125 \mathrm{mg}$ & Rs.42 & Rs.5.48 & 7.66 & 666.4 \\
\hline & $6.25 \mathrm{mg}$ & Rs.60 & Rs.5.83 & 10.29 & 929.2 \\
\hline Tab. Chlorthalidone & $12.5 \mathrm{mg}$ & Rs.55 & Rs.11.31 & 4.86 & 386.3 \\
\hline Tab. Cilnidipine & $10 \mathrm{mg}$ & Rs.71.2 & Rs.18.85 & 3.78 & 277.7 \\
\hline Tab. Clonidine & $100 \mathrm{mcg}$ & Rs.13.75 & Rs.13.75 & 1.00 & 0.0 \\
\hline Tab. Enalapril & $5 \mathrm{mg}$ & Rs.31.18 & Rs.2.86 & 10.90 & 990.2 \\
\hline Inj. Labetalol & $20 \mathrm{mg}$ & Rs.395 & Rs.92 & 4.29 & 329.3 \\
\hline \multirow{2}{*}{ Tab. Losartan } & $25 \mathrm{mg}$ & Rs.5.04 & Rs.5.04 & 1.00 & 0.0 \\
\hline & $50 \mathrm{mg}$ & Rs.62.8 & Rs.9 & 6.98 & 597.8 \\
\hline \multirow{2}{*}{ Tab. Metolazone } & $2.5 \mathrm{mg}$ & Rs.106.9 & Rs.47.83 & 2.23 & 123.5 \\
\hline & $5 \mathrm{mg}$ & Rs.162.09 & 94.2 & 1.72 & 72.1 \\
\hline \multirow{3}{*}{ Tab. Metoprolol } & $25 \mathrm{mg}$ & Rs.39.37 & Rs.5.04 & 7.81 & 681.2 \\
\hline & $50 \mathrm{mg}$ & Rs. 130.55 & Rs.4.76 & 27.43 & $2,642.6$ \\
\hline & $100 \mathrm{mg}$ & Rs.108 & Rs.35.7 & 3.03 & 202.5 \\
\hline \multirow{2}{*}{ Tab. Moxonidine } & $0.2 \mathrm{mg}$ & Rs.61.5 & Rs.54.54 & 1.13 & 12.8 \\
\hline & $0.3 \mathrm{mg}$ & Rs.84 & Rs.75.5 & 1.11 & 11.3 \\
\hline Tab. Nifedipine & $20 \mathrm{mg}$ & Rs.19.95 & Rs.7.09 & 2.81 & 181.4 \\
\hline Inj. Nitroglycerin & $25 \mathrm{mg}$ & Rs.15.805 & Rs. 15.805 & 1.00 & 0.0 \\
\hline \multirow{2}{*}{ Tab. Olmesartan } & $20 \mathrm{mg}$ & Rs.84 & Rs. 15.18 & 5.53 & 453.4 \\
\hline & $40 \mathrm{mg}$ & Rs.148.67 & Rs.26.71 & 5.57 & 456.6 \\
\hline \multirow{2}{*}{ Tab. Prazosin } & $2.5 \mathrm{mg}$ & Rs.99.33 & Rs.8.8 & 11.29 & $1,028.8$ \\
\hline & $5 \mathrm{mg}$ & Rs.76.44 & Rs.9.68 & 7.90 & 689.7 \\
\hline \multirow{2}{*}{ Tab. Ramipril } & $2.5 \mathrm{mg}$ & Rs.48.41 & Rs.6.75 & 7.17 & 617.2 \\
\hline & $5 \mathrm{mg}$ & Rs.76.44 & Rs.9.68 & 7.90 & 689.7 \\
\hline Tab. S-amlodipine & $5 \mathrm{mg}$ & Rs.78.5 & Rs.19.9 & 3.94 & 294.5 \\
\hline \multirow{2}{*}{ Tab. Telmisartan } & $20 \mathrm{mg}$ & Rs.35.49 & Rs.6.73 & 5.27 & 427.3 \\
\hline & $40 \mathrm{mg}$ & Rs.96.39 & Rs.8.7 & 11.08 & $1,007.9$ \\
\hline
\end{tabular}

Table 11: Cost variation among prescribed FDCs and cheapest available.

\begin{tabular}{|lllll|}
\hline Drug Name & $\begin{array}{l}\text { Max cost/10 tab. } \\
\text { (Indian rupees) }\end{array}$ & $\begin{array}{l}\text { Min. cost/10 tab } \\
\text { (Indian rupees) }\end{array}$ & $\begin{array}{l}\text { Cost ratio } \\
\text { Amlodipine+HCT }\end{array}$ & $\begin{array}{l}\text { \% Cost } \\
\text { variation }\end{array}$ \\
\hline Atenolol+Amlodipine & Rs.17.49 & Rs.15 & 3.63 & 263.3 \\
\hline Chlorthalidone+Telmisartan+Cilnidipine & Rs.115 & Rs.103.65 & 4.94 & 394.1 \\
\hline HCT+Telmisartan+Amlodipine & Rs.32.7 & Rs.20 & 1.11 & 11.0 \\
\hline Losartan+Hydrochlorthaizide & Rs.73 & Rs.9 & 8.11 & 63.5 \\
\hline Metoprolol+Amlodipine & Rs.80 & Rs.13.86 & 5.77 & 411.1 \\
\hline Metoprolol+Telmisartan & Rs.120 & Rs.35 & 3.43 & 242.9 \\
\hline Olmesartan+Amlodipine & Rs.117 & Rs.24.32 & 4.81 & 381.1 \\
\hline Olmesartan+Hydrochlorthaizide & Rs.166 & Rs.21.24 & 7.82 & 681.5 \\
\hline Telmisartan+Amlodipine & Rs.121.5 & Rs.11.73 & 10.36 & 935.8 \\
\hline Telmisartan+Chlorthalidone & Rs.98.5 & Rs.15.3 & 6.44 & 543.8 \\
\hline Telmisartan+HCT & Rs.100.7 & Rs.15.3 & 6.58 & 558.2 \\
\hline
\end{tabular}

This discrepancy in the results may be presumed due to the study participants selected and co morbidities included. Our study included only hypertensive and diabetic elderly patients, whereas Nayaka et al, study included all geriatric patients, and our study included co morbidities only of CNS, CVS, RS and locomotor system. ${ }^{17}$ 
Table 12: Cost minimisation analysis.

\begin{tabular}{|ll|}
\hline Class & $\begin{array}{l}\text { Mean } \pm \text { Standard deviation (SD) of } \\
\text { cost/day (Indian rupees) }\end{array}$ \\
\hline C01D & Rs. $15.81 \pm 0.00$ \\
\hline C02A & Rs. $10.75 \pm 10.63$ \\
\hline C02C & Rs. $14.30 \pm 6.17$ \\
\hline C03B & Rs. $12.95 \pm 6.13$ \\
\hline C07A & Rs. $24.97 \pm 77.94$ \\
\hline C08C & Rs. $3.96 \pm 2.43$ \\
\hline C09A & Rs. $4.75 \pm 1.51$ \\
\hline C09C & Rs. $6.26 \pm 3.05$ \\
\hline
\end{tabular}

In this study $51.5 \% \quad(\mathrm{n}=85)$ underwent fundoscopic examination, and among 85 patients DR was seen in $72.94 \%(n=62)$ patients and hypertensive retinopathy was seen in $63.52 \%(n=54)$. In the study conducted by Gupta et al, in patients with essential HTN, hypertensive retinopathy was seen in $83.78 \%(n=37)$ of patients with age more than 60 years. ${ }^{18}$ In the study conducted by Gadkari et al, in patients with DM, DR was seen in patients within the age group of 60-80 years and >80years was $25.04 \%(n=1789)$ and $23.21 \%(n=56) .{ }^{19}$

Table 13: Cost minimisation analysis of antihypertensive FDCs.

\begin{tabular}{|ll|}
\hline CLASS & Mean \pm SD of cost/day (Indian rupees) \\
\hline C07F & Rs. $2.96 \pm 3.42$ \\
\hline C08G & Rs. $5.45 \pm 0.00$ \\
\hline C09D & Rs. $8.65 \pm 3.58$ \\
\hline
\end{tabular}

Table 14: BP, BS, HbA1c levels in the study population.

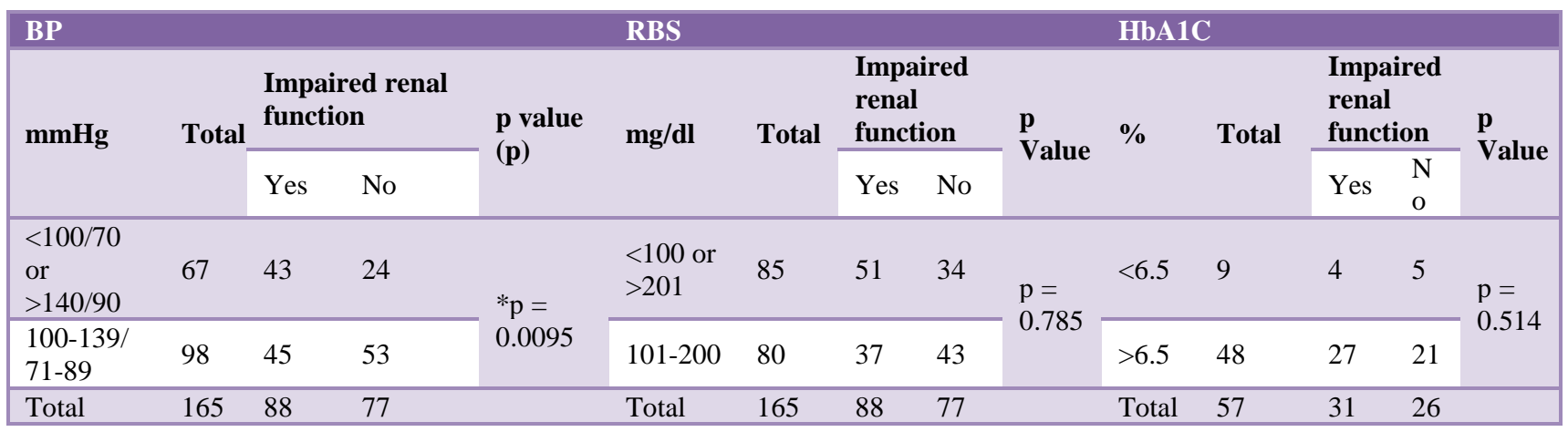

*p $<0.05$ was considered significant

Table 15: Total number of days in the hospital per patient in the study population.

\begin{tabular}{|lll|}
\hline \multicolumn{2}{c}{ No. of days in hospital } \\
\hline Impaired renal function & Mean & Std. Deviation \\
\hline No & 8.53 & 6.429 \\
\hline Yes & 8.73 & 7.464 \\
\hline Total & 8.64 & 6.980 \\
\hline
\end{tabular}

\section{Renal function}

This study revealed that more than half, $53.3 \%(n=88)$ of patients had impaired renal function and $46.7 \%(n=77)$ had normal renal function compared to a similar study by Shah et al, $38 \%(\mathrm{n}=19)$ had impaired renal function and $62 \%$ $(n=31)$ had normal renal function, suggesting the importance of screening of renal function in hypertensive diabetic patients. ${ }^{11}$

Table 16: Drug utilisation in our study population as per WHO indicators.

\begin{tabular}{|c|c|c|c|}
\hline & \multirow{2}{*}{ Total } & \multicolumn{2}{|c|}{ Impaired renal function } \\
\hline & & Yes & No \\
\hline Average number of drugs per patient with active drugs in FDCs & $1.60 \pm 0.936$ & $1.70 \pm 1.074$ & $1.48 \pm 0.736$ \\
\hline Percentage of drugs prescribed by generic names & $8.85 \%$ & - & - \\
\hline Percentage of encounters with injection prescribed & $2.21 \%$ & - & - \\
\hline Percentage of drugs prescribed from essential drug list 2015 & $32.30 \%$ & - & - \\
\hline
\end{tabular}

\section{Anti-hypertensive medications}

A total of 226 anti-hypertensive medications were given to 165 patients, 191 among them were single drug and 35 were FDCs and a total of 128 drugs were prescribed for patients with impaired renal function. There was a significant difference in the number of anti-hypertensive drugs prescribed in patients with impaired renal function and in patients with normal renal function, $(\mathrm{p}<0.05)$. Among the single drug given to the patients, class ARBs 
were in majority, $42.4 \% \quad(n=81)$ followed by CCBs, $34.66 \%(n=66), \beta$ blockers, $25 \% \quad(n=13)$, angiotensin converting enzyme inhibitors (ACEIs), 3.66\% ( $n=7)$, centrally acting sympathetic drugs and thiazide/thiazide like diuretics, $2.09 \% \quad(n=4)$ each, $\alpha$ blockers and vasodilators, $1.05 \%(\mathrm{n}=2)$ each. Our study is similar to the study conducted by Shah et al, where $60 \%$ where ACEIs/ARBs followed by CCBs (24\%), $\beta$ blockers $(20 \%) .{ }^{11}$ Similar study conducted by Patta S, on geriatric and non-geriatric hypertensive patients ARBs was used in majority $(22.7 \%)$ followed by CCBs. ${ }^{20}$ ACEIs and ARBs prevents microvascular complications and can prevent progression of renal damage in addition to lowering BP.

Our study coincides with the JNC 7 guidelines for treatment of hypertensive diabetic patients. ${ }^{8}$ In our study $61.2 \%(\mathrm{n}=101)$ patients were on monotherapy. Among patients with impaired renal function $30.91 \%(n=51)$ were on monotherapy. The maximum number of drugs/patient including active drugs in FDCs were six in patients with impaired renal function and four in patients with normal renal function. Among patients with impaired renal function, 150 drugs were prescribed including active drugs in FDCs. A significant difference in the number of drugs used in HTN among patients with impaired renal function and in patients with normal renal function $(\mathrm{p}<0.05)$ was seen. ARBs were the most preferred class $22 \%(n=42)$ amidst patients with impaired renal function, followed by CCBs $17.8 \% \quad(n=34)$ whereas study by Elhami et al, revealed that ACEIs was the most common drug prescribed, $55.5 \%(\mathrm{n}=20)$ among single drug therapy. ${ }^{21}$ This inconsistency in results is because of the study population, our study included patients with and without impaired renal function whereas Elhami et al, study included all CKD patients. ${ }^{21}$

\section{Dosage}

Our study population PDD/DDD ratio ranged between (0.03-3.33), least being for labetalol and maximum for nifedipine (3.33), whereas a study conducted by Solanki et al, the range was (0.607-1.782), least being for metoprolol and maximum for amlodipine. ${ }^{22}$ The range of PDD/DDD for drugs with impaired renal function was (0.03-3.33) suggesting that there was no difference in range between dose prescribed in normal renal function and impaired renal function, although there was a slight increase in the PDD/DDD ratio of amlodipine and telmisartan in patients with impaired renal function when compared to patients with normal renal function.

\section{FDCs}

Among 35 FDCs prescribed, the most common class of FDCs was combinations with ARB, 85.7\% (n=30) of which telmisartan + HCT was the most common $(34.29 \%)$ followed by telmisartan + amlodipine (17.14\%). Only $11.43 \%(\mathrm{n}=4)$ combination included three drugs. Among patients with impaired renal function, $57.1 \%(n=20)$ FDCs were prescribed of which combinations of ARB was most common $51.4 \%(n=18)$, with telmisartan + HCT most commonly prescribed $25.7 \%(\mathrm{n}=9)$. In the study conducted by R Y Pavitra et al, $66.6 \%$ were prescribed two drug combinations and $30 \%$ three drugs combinations. Two drugs combinations commonly used were cilnidipine + torsemide $(52 \%)$, amlodipine + furosemide $(28 \%)$ and metoprolol + cilnidipine $(11 \%){ }^{23}$

\section{Cost analysis}

Our study showed a high fluctuation in the minimum and maximum price of anti-hypertensive drugs. The cost ratio was high and percentage cost variation was seen to be more than $100 \%$ in most of the drugs. Our study was similar to the study conducted by Kamath et al, in Bangalore showed high price variation. ${ }^{14}$ The result of cost evaluation showed that CCBs had the lowest cost/day when compared to other class of anti-hypertensives and combination of $\beta$ blocker and CCB was the lowest cost/day FDC prescribed. The results of the study were different when compared to study conducted by Rachana et al, where diuretics had the lowest cost. This discrepancy may be due to diuretics not routinely being prescribed in our study. ${ }^{24}$ In a developing country like India, one of the smartest ways to reduce the prescription costs is to use the generics. Even though the Medical Council of India have insisted on prescribing the generic drugs as far as possible, doctors are reluctant to write prescriptions containing only generic or unbranded chemical name of drugs. All too often, the physicians and the patients prefer the expensive brand name drugs because they believe that the generic equivalent is inferior. In our study only $8.85 \%$ of drugs are prescribed on the basis of their generic names.

\section{CONCLUSION}

This study provided a baseline data regarding the prescribing pattern in hypertensive diabetic in-patients. There is adherence to the JNC 7 guidelines although there is scope for improvement, especially in prescribing generic names. Since hypertension is a common lifelong disorder, prescription cost is one of the major reasons for no adherence to drug therapy. Further studies from every now and then are required in drug utilization pattern and standard treatment guidelines to be circulated among prescribing clinicians.

\section{ACKNOWLEDGEMENTS}

Authors would like to thank the encouragement, support and valuable suggestions provided by the teaching and non-teaching staff of Department of Pharmacology and Department of Medicine, SDM College of Medical Sciences and Hospital, Dharwad.

\section{Funding: No funding sources}

Conflict of interest: None declared

Ethical approval: The study was approved by the Institutional Ethics Committee 


\section{REFERENCES}

1. Swami S, Swami SC, Patel VW, Kanhere AM. Review article hypertension and diabetes in India: A Review. Inter J Clin Biochem Res. 2015;2(1):54-8.

2. Nagaraju K, Manasa S, Manjunath R. Pharmacovigilance study in geriatric population. Asian J Pharm Clin Res. 2015;8(2):395-9.

3. Franchini M, Pieroni S, Fortunato L, Molinaro S, Liebman M. Poly-Pharmacy among the Elderly: Analysing the Co-Morbidity of Hypertension and Diabetes. Curr Pharm Des. 2015;21(6):791-805.

4. Jhaveri BN, Patel TK, Barvaliya MJ, Tripathi CB. Drug utilization pattern and pharmacoeconomic analysis in geriatric medical in-patients of a tertiary care hospital of India. J Pharmacol Pharmacother. 2014;5(1):15-20.

5. Mohan V, Seedat YK, Pradeepa R. The Rising burden of diabetes and hypertension in Southeast Asian and African regions: Need for effective strategies for prevention and control in primary health care settings. Int $\mathbf{J}$ Hypertens. 2013;2013:1-14.

6. Dutta M, Prashad L. Prevalence and risk factors of polypharmacy among elderly in India: evidence from sage data. IJPMN. 2015;2(2):11-4.

7. Altaf M, Rasheed A, Mujtaba A, Mohammed S. Drug utilisation evaluation of antihypertensives in geriatric patients in a tertiary care hospital J P. Int Pharm Pharm Sci. 2014;6(9):9-12.

8. Chobaniana AV, Bakris GL, Black HR, Cushman WC, Green LA, Izzo J L, et al. Seventh report of the Joint National Committee on prevention, detection, evaluation, and treatment of high blood pressure. Hypertension. 2003;42(6):1206-52.

9. Munger MA. Polypharmacy and combination therapy in the management of hypertension in elderly patients with co-morbid diabetes mellitus. Drugs Aging. 2010;27(11):871-8.

10. Pourhoseingholi MA, Vahedi M, Rahimzadeh M. Sample size calculation in medical studies. Gastroenterol Hepatol Bed Bench. 2013;6(1):14-7.

11. Shah J, Khakhkhar T, Bhirud S, Shah RB, Date S. Study of utilization pattern of antihypertensive drugs in hypertensive diabetic patients with or without reduced renal function at tertiary care teaching hospital. Int J Med Sci Public Health. 2013;2(2):175-80.

12. Bureau of Pharma PSU of India. Jan Aushadhi: An Initiative of Government of India. India: National Informatics centre. Pradhan Mantri Bhartiya Jan Aushadhi pariyojna-Price list, 2017. Available at: http://janaushadhi.gov.in/data/MRP_March17.pdf. Cited 2017 April.

13. National Pharmaceutical Pricing authority. NPPA: Affordable medicines to all. India: National Informatics centre. Pharma Sahi Daam. Available at: http://nppaindia.nic.in/nppaprice/pharmasahidaamweb.a spx.
14. Kamath L, Satish GR. Cost variation analysis of antihypertensive drugs available in Indian market: an economic perspective. IJPSR. 2016;7(5):2050-6.

15. Ferreira JP, Girerd N, Pellicori P, Duarte K, Girerd S, Pfeffer MA, et al. Renal function estimation and Cockcroft-Gault formulas for predicting cardiovascular mortality in population-based, cardiovascular risk, heart failure and post-myocardial infarction cohorts: The Heart 'OMics' in AGEing (HOMAGE) and the high-risk myocardial infarction database initiatives. BMC medicine. 2016;14(1):181.

16. Abraham F, Varughese G, Mathew J C, John P M, Sam G K. Drug utilization pattern among geriatric patients in a tertiary care teaching hospital. Asian J Pharm Clin Res. 2015;8(6):191-4.

17. Nayaka SR, Rajeshwari B, Venkatadri TV. Drug utilization pattern in geriatric inpatients of medicine department in a tertiary care teaching hospital. Int J Basic Clin Pharmacol. 2015;4(3):568-73.

18. Gupta RP, Gupta S, Gahlot A, Sukharamwala D, Vashi J. Evaluation of hypertensive retinopathy in patients of essential hypertension with high serum lipids. Med J Dr. D.Y. Patil University. 2013;6(2):165-9.

19. Gadkari SS, Maskati QB, Nayak BK. Prevalence of diabetic retinopathy in India: The All India Ophthalmological Society Diabetic Retinopathy Eye Screening Study 2014. Ind J Ophthalmol. 2016;64:38-44.

20. Patta S. Drug Utilization Pattern of Antihypertensives in Geriatric and Non Geriatric Population in a Tertiary Care Government Hospital Srikakulum, A.P. J Evol Med Dent Sci. 2015;04(13):2101-6.

21. Chobanian AV, Bakris GL, Black HR, Cushman WC, Green LA, Izzo Jr JL, et al. The seventh report of the joint national committee on prevention, detection, evaluation, and treatment of high blood pressure: the JNC 7 report. JAMA. 2003;289(19):2560-71.

22. Solanki KC, Mistry RA, Singh AP, Jadav SP, Patel NM, Trivedi HR. Drug utilization study of anti-hypertensive drugs and their adverse effects in patients of a tertiary care hospital. J Clin Exp Res. 2013;1(3):59-67

23. Pavitra RY, Geeta M, Aggarwal R, Somashekhar HS. Drug utilization pattern of antihypertensive drugs in chronic kidney disease patients in a tertiary care hospital. J Den MedSci. 2014;13(11):23-7.

24. Rachana PR, Anuradha HV, Shivamurthy MC. Antihypertensive prescribing patterns and cost analysis for primary hypertension: A retrospective study. J Clin Diag Res. 2014;8(9):19-22.

Cite this article as: Bhandary A, Bhandari PR. Drug usage pattern of anti-hypertensive drugs in elderly diabetic, hypertensive in-patients with or without impaired renal function in a tertiary care hospital. Int J Basic Clin Pharmacol 2018;7:696-706. 